\title{
A thermodynamic principle for the coupled bioenergetic processes of ATP synthesis
}

\author{
Sunil Nath \\ Department of Biochemical Engineering and Biotechnology, Indian Institute of \\ Technology, Hauz Khas, New Delhi 110 016, India
}

\begin{abstract}
Based on a nonequilibrium thermodynamic description of the coupled bioenergetic processes of ATP synthesis, I show for the first time that the entropy production depends on the physical system of coupling; completely delocalized coupling leads to minimum rate of entropy production in the steady state. Further, when nonlinear processes are considered, the free energy dissipation exhibits a minimum at the operating distance from equilibrium. These results agree with experimental observations. The principle proposed here accurately predicts the coupling system and the distance from equilibrium in fundamental life processes.
\end{abstract}

\section{INTRODUCTION}

The fundamental bioenergetic processes of life are all nonequilibrium processes. The energy acquired by living cells is stored in useful form mainly as molecules of adenosine triphosphate (ATP). ATP, in converting to adenosine diphosphate (ADP) releases the stored energy and supplies it to the organism for the performance of vital functions (1). It is essential that ATP be in nonequilibrium with ADP; otherwise it will not release the stored energy (about $60 \mathrm{~kJ} / \mathrm{mol}$ ATP under actual operating conditions). Thus, a biological system at equilibrium is dead.

The synthesis of ATP takes place in the mitochondria of cells, starting from oxidation of organic compounds by the process of oxidative phosphorylation with surprisingly high efficiency. The intriguing question is how oxidation and ATP production are coupled and both delocalized (1-4) and localized (4-7) systems of coupling have been proposed. According to the delocalized theory, electron transfer through the respiratory chain leads to pumping of protons across the membrane and formation of a bulk proton electrochemical potential gradient, $\Delta \mu_{\mathrm{H}}$. This bulk gradient drives the ATP reaction and constitutes the sole connection between oxidation and ATP synthesis. The localized models, on the other hand, postulate direct intramembrane coupling between oxidation and phosphorylation.

Several observations, several experimental measurements of fluxes and forces have been made on ATP producing systems (8-15). But what do these numbers add up to? What do the localized and delocalized systems of coupling mean in terms of entropy production? Can a variational principle be found which summarizes these measurements and provides a new way of thinking? Such a principle is delightful, beautiful, and at the same time, powerful; with it we can predict new things, such as the distance from equilibrium at which a nonequilibrium system operates, even in the absence of detailed information about the system. The development of such a principle is the aim of this paper. 


\section{NONEQUILIBRIUM THERMODYNAMIC MODEL OF ATP SYNTHESIS}

Applying the principles of nonequilibrium thermodynamics (16) to ATP synthesis leads to the following flux-force relationships:

$$
\begin{aligned}
& \mathrm{J}_{\mathrm{O}}=\mathrm{L}_{\mathrm{OO}} \mathrm{A}_{\mathrm{O}}+\mathrm{L}_{\mathrm{OH}} \Delta \mu_{\mathrm{H}}+\mathrm{L}_{\mathrm{OP}} \mathrm{A}_{\mathrm{P}} \\
& \mathrm{J}_{\mathrm{H}}=\mathrm{L}_{\mathrm{HO}} \mathrm{A}_{O}+\mathrm{L}_{\mathrm{HH}} \Delta \mu_{\mathrm{H}}+\mathrm{L}_{\mathrm{HP}} \mathrm{A}_{\mathrm{P}} \\
& \mathrm{J}_{\mathrm{P}}=\mathrm{L}_{\mathrm{PO}} \mathrm{A}_{\mathrm{O}}+\mathrm{L}_{\mathrm{PH}} \Delta \mu_{\mathrm{H}}+\mathrm{L}_{\mathrm{PP}} \mathrm{A}_{\mathrm{P}}
\end{aligned}
$$

where A represents the affinity of the oxidation (O) and ATP (P) reactions and $\Delta \mu_{\mathrm{H}}$ the electrochemical potential difference across the inner mitochondrial membrane. The $\mathrm{J}_{i} \mathrm{~s}$ stand for fluxes and the $\mathrm{L}_{\mathrm{ij}} \mathrm{s}$ for the phenomenological coefficients.

The net proton flux $\mathrm{J}_{\mathrm{H}}$ due to oxidation (negative) and transport through ATPase and passive channels (positive) can be written as

$$
\mathrm{J}_{\mathrm{H}}=-\mathrm{n}_{\mathrm{O}} \mathrm{J}_{\mathrm{O}}+\mathrm{C}_{\mathrm{H}} \Delta \mu_{\mathrm{H}}+\mathrm{n}_{\mathrm{P}} \mathrm{J}_{\mathrm{P}}
$$

with $\mathrm{n}_{0}$ and $\mathrm{n}_{\mathrm{p}}$ as the stoichiometries of the redox and ATPase pumps.

Combining eqns. $1-4$, for the stationary steady state of zero proton flux leads to

$$
\begin{aligned}
& \mathrm{J}_{\mathrm{O}}=\left[\mathrm{L}_{\mathrm{OO}}-\left(\mathrm{L}_{\mathrm{OH}} \mathrm{L}_{\mathrm{HO}}\right) / \mathrm{L}_{\mathrm{HH}}\right] \mathrm{A}_{\mathrm{O}}+\left[\mathrm{L}_{\mathrm{OP}}-\left(\mathrm{L}_{\mathrm{OH}} \mathrm{L}_{\mathrm{HP}}\right) / \mathrm{L}_{\mathrm{HH}}\right] \mathrm{A}_{\mathrm{P}} \\
& \mathrm{J}_{\mathrm{P}}=\left[\left(\mathrm{L}_{\mathrm{PO}}-\left(\mathrm{L}_{\mathrm{PH}} \mathrm{L}_{\mathrm{HO}}\right) / \mathrm{L}_{\mathrm{HH}}\right] \mathrm{A}_{\mathrm{O}}+\left[\left(\mathrm{L}_{\mathrm{PP}}-\left(\mathrm{L}_{\mathrm{PH}} \mathrm{L}_{\mathrm{HP}}\right) / \mathrm{L}_{\mathrm{HH}}\right] \mathrm{A}_{\mathrm{P}}\right.\right. \\
& \Phi=\left[\left\{\mathrm{L}_{\mathrm{OO}}-\left(\mathrm{L}_{\mathrm{OH}} \mathrm{L}_{\mathrm{HO}}\right) / \mathrm{L}_{\mathrm{HH}}\right\}+\left\{\mathrm{L}_{\mathrm{OP}}-\left(\mathrm{L}_{\mathrm{OH}} \mathrm{L}_{\mathrm{HP}}\right) / \mathrm{L}_{\mathrm{HH}}\right\}\left(\mathrm{A}_{\mathrm{P}} / \mathrm{A}_{\mathrm{O}}\right)\right. \\
& \left.+\left\{\mathrm{L}_{\mathrm{PO}}-\left(\mathrm{L}_{\mathrm{PH}} \mathrm{L}_{\mathrm{HO}}\right) / \mathrm{L}_{\mathrm{HH}}\right\}\left(\mathrm{A}_{\mathrm{P}} / \mathrm{A}_{O}\right)+\left\{\mathrm{L}_{\mathrm{PP}}-\left(\mathrm{L}_{\mathrm{PH}} \mathrm{L}_{\mathrm{HP}}\right) / \mathrm{L}_{\mathrm{HH}}\right\}\left(\mathrm{A}_{\mathrm{P}} / \mathrm{A}_{\mathrm{O}}\right)^{2}\right] \mathrm{A}_{\mathrm{O}}^{2}
\end{aligned}
$$

where $\Phi$ represents the dissipation of free energy per unit time due to irreversible processes. There exists experimental evidence for the validity of linear flux-force relationships (eqns. 1 3) as well as the Onsager reciprocal relations for ATP synthesis in biological systems (15), i.e.

$$
\mathrm{L}_{\mathrm{OH}}=\mathrm{L}_{\mathrm{HO}}, \quad \mathrm{L}_{\mathrm{OP}}=\mathrm{L}_{\mathrm{PO}}, \quad \mathrm{L}_{\mathrm{PH}}=\mathrm{L}_{\mathrm{HP}}
$$

However, one central element is nonlinear with $\Delta \mu_{\mathrm{H}}$ : the nonohmic proton leak. This will be taken into account towards the end. 
The second law of thermodynamics further imposes the conditions that $\Phi, \mathrm{L}_{\mathrm{OO}}, \mathrm{L}_{\mathrm{HH}}$ and $\mathrm{L}_{\mathrm{PP}}$ be positive and that $\mathrm{L}_{\mathrm{OH}}^{2} \leq \mathrm{L}_{\mathrm{OO}} \mathrm{L}_{\mathrm{HH}}, \mathrm{L}_{\mathrm{OP}}^{2} \leq \mathrm{L}_{\mathrm{OO}} \mathrm{L}_{\mathrm{PP}}$ and $\mathrm{L}_{\mathrm{PH}}^{2} \leq \mathrm{L}_{\mathrm{PP}} \mathrm{L}_{\mathrm{HH}}$ be satisfied. Further, in accordance with the adopted sign criteria, $\mathrm{L}_{\mathrm{OH}} \leq 0, \mathrm{~L}_{\mathrm{OP}} \geq 0$ and $\mathrm{L}_{\mathrm{PH}} \geq 0$. Both localized and delocalized coupling can be described by the equations developed above; $\mathrm{L}_{\mathrm{OP}}=0$ (completely delocalized coupling) implies the absence of direct coupling between oxidation and phosphorylation. The value of $\mathrm{L}_{\mathrm{OP}}$ corresponding to the completely localized process $\left(\Delta \mu_{\mathrm{H}}=\right.$ $0)$ is $\mathrm{L}_{\mathrm{OP}}=\mathrm{q}\left(\mathrm{L}_{\mathrm{OO}} \mathrm{L}_{\mathrm{pP}}\right)^{1 / 2}=3.80$ in order to obtain the same degree of coupling $(\mathrm{q}=0.982)$ as in the completely delocalized process. Experimental data for the straight phenomenological coefficients (16) are as follows: $\mathrm{L}_{\mathrm{OO}}=1.9$ natom $\mathrm{O} /(\mathrm{mg} \min \mathrm{mV}), \mathrm{L}_{\mathrm{PP}}=7.9 \mathrm{nmol} \mathrm{ATP} /(\mathrm{mg}$ $\min \mathrm{mV})$ and $\mathrm{C}_{\mathrm{H}}=3.2 \mathrm{nmol} \mathrm{H} \mathrm{H}^{+}(\mathrm{mg} \mathrm{min} \mathrm{mV})$.

\section{Proposed principle and entropy production}

The preceding nonequilibrium thermodynamic analysis permits a clear differentiation between kinetic (i.e. permeability-related) factors as specified by the coupling coefficients $L_{i j}$ or by $Z$ and $q$ and energetic (chemical, affinity-related) factors contained in the affinity force ratio, $A_{p} / A_{0}$, which depends on the concentrations of the species involved in the reactions. The dissipation function-affinity ratio curves for oxidative phosphorylation in rat liver mitochondria are plotted in Fig. 1 for both localized and delocalized systems of coupling using the experimentally determined value of $A_{o}(208 \mathrm{~kJ} / \mathrm{mol})(8,9,13,15)$. The free energy dissipation is clearly seen to be dependent on the system of coupling; from Fig. 1, the delocalized system of coupling has the property that it generates entropy at a minimum rate over the entire range of force ratios in oxidative phosphorylation, compared to any other system of coupling. Needless to say, even

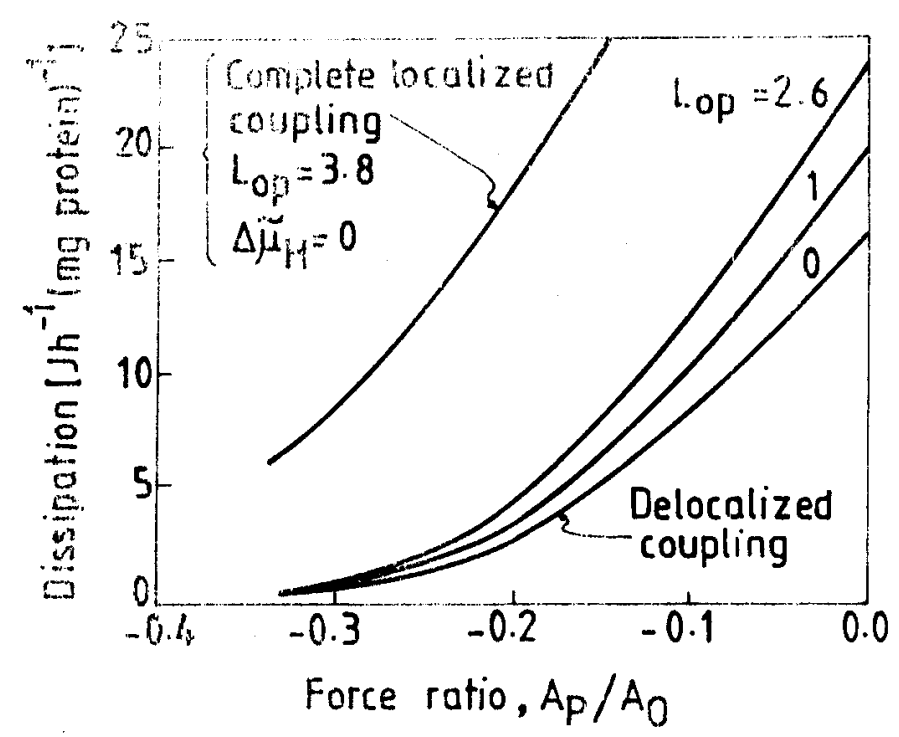

Fig. 1. Entropy production in oxidative phosphorylation; dissipation of free energy as a function of the force ratio for completely localized $\left(\mathrm{L}_{\mathrm{OP}}=3.8, \Delta \mu_{\mathrm{H}}=0\right)$, localized $\left(\mathrm{L}_{\mathrm{OP}}=1,2.6\right)$ and completely delocalized $\left(\mathrm{L}_{\mathrm{OP}}=0\right)$ systems of coupling. The curves were generated using eqn. 7 for 3-hydroxybutyrate as substrate. Redox and ATPase pump stoichiometries $\left(n_{0}, n_{p}\right)$ were taken as $12 \mathrm{H}^{+} / \mathrm{O}$ and $4 \mathrm{H}^{+}$/ATP respectively and the experimentally determined value of $\mathrm{A}_{0}$ $(208 \mathrm{~kJ} / \mathrm{mol})(8,9,13,15)$ was used. 
small differences in the rate of entropy production among various systems can lead to substantial changes in the free energy dissipation when integrated over the lifetime of the organism. Thus, the entropy production provides insightful physical significance for the selection of a delocalized coupling system. Changes in the structure of the cell, in the permeability of the membrane change the coupling coefficients, alter the physical system of the cell and optimize the kinetic factors i.e. evolution tunes the system for minimum. $\mathbf{\Phi}$. Similar results are obtained for other values of the straight phenomenological coefficients.

What then are the operating affinity ratios during ATP production (state 3)? To answer this, one needs to consider the $\mathrm{P} / \mathrm{O}$ ratio

$$
P / O=J_{P} / J_{O}=Z \frac{q+Z\left(A_{P} / A_{O}\right)}{1+q Z\left(A_{P} / A_{O}\right)}
$$

and the phosphorylation efficiency which is $-\left(\mathrm{A}_{\mathrm{P}} / \mathrm{A}_{0}\right)$ times the $\mathrm{P} / \mathrm{O}$ ratio. This is represented in Fig. 2 for delocalized coupling with succinate and 3-hydroxybutyrate as substrate. The $\mathrm{P} / \mathrm{O}$ ratio is seen to depend on the distance from equilibrium and is always removed from the values of 3 for 3-hydroxybutyrate and 2 for succinate, while the efficiency of energy conversion exhibits a maxima at the operating affinity ratios $\left(A_{\mathrm{p}} / \mathrm{A}_{0}=-0.265\right)$ (Fig. 2$)$. The calculated $\mathrm{Z}$ and $\mathrm{q}$ are identical to the values determined experimentally $(8,9)$. For instance, with 3 -hydroxybutyrate, the value of the coupling coefficient, $q$ is 0.98 by experiment and 0.982 by the delocalized theory. A P/O ratio of 3 for 3-hydroxybutyrate implies a 15-fold higher dissipation compared to operation at an affinity ratio of -0.265 (Fig. 1). Thus the system stays as close to equilibrium as possible in order to minimize $\Phi$. However, it does not function at affinity ratios considerably below $-0.265(-0.365$ for succinate) because of the low efficiency of energy conversion; moreover a certain $\mathrm{P} / \mathrm{O}$ ratio needs to be maintained by the organism. Thus the kinetic factors are selected to minimize the dissipation of free energy (movement along the y-axis in Fig. 1) while the energetic factors are optimized (movement along the $x$-axis in Fig. 2) to maximize the efficiency of energy conversion. This principle accurately predicts the values of the affinity ratios for ATP synthesis in rat liver mitochondria found experimentally by several researchers (8-15).

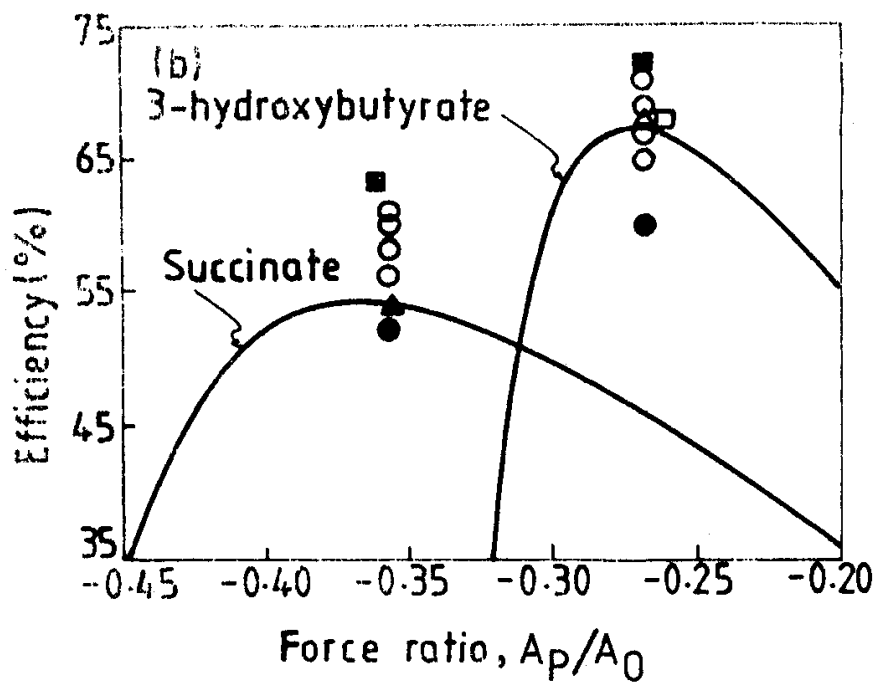

Fig. 2. Efficiency as a function of the affinity ratio for oxidative phosphorylation in rat liver mitochondria with succinate and 3-hydroxybutyrate as substrate; solid lines represent theoretical curves for delocalized coupling using eqn. 9. Experimental data for $J_{p}, J_{O}, A_{p}$ and $A_{0}$ : $[O](8$,

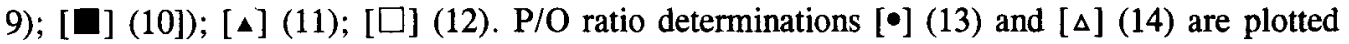
along with $A_{P}, A_{0}$ measurements $(8,9)$. 


\section{Inclusion of nonlinear processes}

The above principle can be refined further if the experimentally obtained nonlinear variation of the proton leak with $\Delta \mu_{\mathrm{H}}(13,17)$ is taken into account. $\Delta \mu_{\mathrm{H}}$ can be written in terms of the potential and concentration differences, i.e.

$$
\Delta \mu_{\mathrm{H}}=\mathrm{F} \Delta \psi-2.3 \mathrm{RT} \Delta \mathrm{pH}
$$

where $\mathrm{F}$ is the value of the Faraday. One can either assume equivalence of $\Delta \psi$ and $\Delta \mathrm{pH}$ or consider both components of $\Delta \mu_{\mathrm{H}}$. In the former case, for instance, the proton leak is about four times larger in state 4 as compared to state 3 (17). Using these facts, an analysis with the nonlinear proton leak is carried out for the first time and the result is illustrated in Fig. 3. The free energy dissipation now shows a minimum at the operating distance from equilibrium. Thus, now, both kinetic and energetic factors are selected and tuned by the biological system.

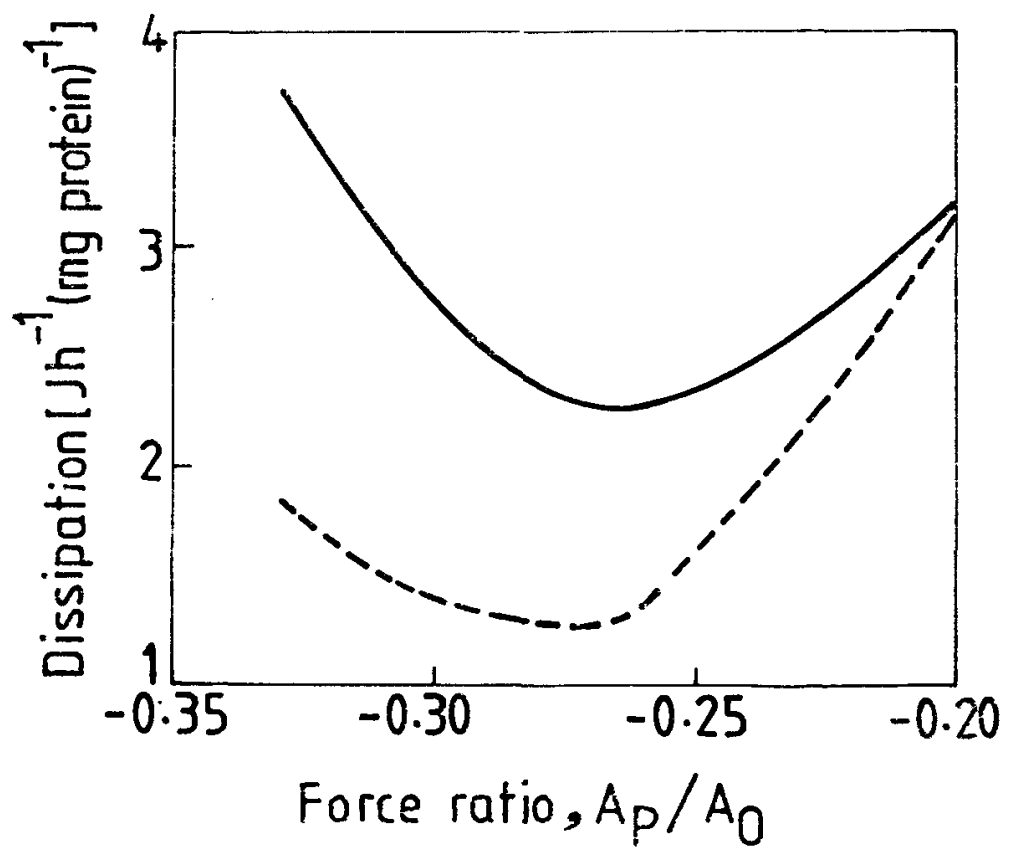

Fig. 3. Free energy dissipation vs. affinity ratio for delocalized coupling with 3-hydroxybutyrate as substrate, taking the nonlinear dependence of the $\mathrm{H}^{+}$leak on $\Delta \mu_{\mathrm{H}}$ into account. Dashed lines represent results obtained taking only the $\Delta \psi$ part of $\Delta \mu_{\mathrm{H}}$ and assuming equivalence of $\Delta \psi$ and $\Delta \mathrm{pH}$ while bold lines show the results when both components of $\Delta \mu_{\mathrm{H}}$ are considered (17).

\section{Differences from Prigogine's principle and concluding remarks}

I have several remarks on the principle formulated here. It is valid, strictly speaking, for linearly coupled systems close to equilibrium satisfying Onsager symmetry; however, it appears to have a validity beyond these restrictions. It differs from Prigogine's principle (18) for linearly coupled processes which compares the minimum entropy produced by stationary steady states (e.g. those of zero $\mathrm{H}^{+}$flux) with other nonstationary states for a single physical system, while the principle formulated here is applicable to different physical systems all of which are at stationary state of zero $\mathrm{H}^{+}$flux. As in Hill's work (19), the rate of entropy production increases quadratically with the driving force, but unlike there, coupled processes taking place in opposite directions are 
considered here and no requirement that dissipation curves cross each other is imposed. The principle presented here is found to apply for different oxidation substrates and for nonlinear proton leaks and points to the wisdom of living organisms. It may well prove to be a general thermodynamic principle, applicable to a wide range of fundamental life processes.

\section{ACKNOWLEDGEMENTS}

I thank Professors Britton Chance, Peter Hinkle and Ganpathy Murthy for stimulating discussions. This research was supported by a Department of Science and Technology, India Grant SR/OY/GB-26/93, an All India Council for Technical Education Career Award 1$52 / \mathrm{CD} / \mathrm{CA} / 94-95$, and a fellowship from the United Nations Development Program, all of which are fondly acknowledged.

\section{REFERENCES}

1. P. C. Hinkle and R. E. McCarty, Sci. Am. 283, 104-123 (1978).

2. P. Mitchell, Nature 191, 144-148 (1961).

3. S. Ogawa and T. M. Lee J. Biol. Chem. 259, 10004-10011 (1984).

4. A. E. Senior Physiol. Rev. 68, 177-231 (1988).

5. H. Rottenberg Mod. Cell. Biol. 4, 47-83 (1985).

6. S. J. Ferguson Biochim. Biophys. Acta 811, 47-95 (1985).

7. H. V. Westerhoff, B. A. Melandri, G. Venturoli, G. F. Azzone and D. B. Kell Biochim. Biophys. Acta 768, 257-292 (1984).

8. J. J. Lemasters J. Biol. Chem. 259, 13123-13130 (1984).

9. J. J. Lemasters, R. Grunwald and R. K. Emaus J. Biol. Chem. 259, 3058-3063 (1984).

10. H. Rottenberg. In Progress in Surface and Membrane Science ( J. F. Danielli, ed.) 12, 245-325 Academic Press, New York (1978).

11. E. C. Slater, J. Rosing and A. Mol Biochim. Biophys. Acta 292, 534-553 (1973).

12. D. G. Nichols Eur. J. Biochem. 50, 305-315 (1974).

13. P. C. Hinkle, M. Arun Kumar, A. Resetar and D. L. Harris Biochemistry 30, 3576-3582 (1991).

14. C. D. Stoner J. Biol. Chem. 262, 10445-10453 (1987).

15. J. W. Stucki Eur. J. Biochem. 109, 269-283 (1980).

16. D. Jou and J. E. Llebot. Introduction to the Thermodynamics of Biological Processes. Prentice Hall, Englewood Cliffs, New Jersey, USA (1990).

17. G. Krishnamoorthy and P. C. Hinkle Biochemistry 23, 1640-1645 (1984).

18. I. Prigogine. Introduction to Thermodynamics of Irreversible Processes. Wiley-Interscience, New York (1967).

19. A. Hill Nature 348, 426-428 (1990). 